University of New Orleans

ScholarWorks@UNO

3-12-2009

\title{
Synthesis of Magnetic Porous Hollow Silica Nanotubes for Drug Delivery
}

H. Ma

University of New Orleans

J. Tarr

University of New Orleans

M. A. DeCoster

Louisiana Tech University

J. McNamara

Louisiana Tech University

D. Caruntu

University of New Orleans, dcaruntu@uno.edu

See next page for additional authors

Follow this and additional works at: https://scholarworks.uno.edu/chem_facpubs

Part of the Materials Science and Engineering Commons, and the Physics Commons

\section{Recommended Citation}

H. Ma, J. Tarr, M.A. DeCoster, J. McNamara, D. Caruntu, J.F. Chen, C.J. O'Connor, W.L. Zhou,“Synthesis of Magnetic Porous Hollow Silica Nanotubes for Drug Delivery," J. Appl. Phys., 2009, 105(7), 07B309/

1-07B309/3.

This Article is brought to you for free and open access by the Department of Chemistry at ScholarWorks@UNO. It has been accepted for inclusion in Chemistry Faculty Publications by an authorized administrator of ScholarWorks@UNO.For more information, please contact scholarworks@uno.edu. 


\section{Authors}

H. Ma, J. Tarr, M. A. DeCoster, J. McNamara, D. Caruntu, J. F. Chen, Charles J. O'Connor, and Weilie Zhou 


\section{AIP Applied Physics}

\section{Synthesis of magnetic porous hollow silica nanotubes for drug delivery}

H. Ma, J. Tarr, M. A. DeCoster, J. McNamara, D. Caruntu et al.

Citation: J. Appl. Phys. 105, $07 B 309$ (2009); doi: 10.1063/1.3072048

View online: http://dx.doi.org/10.1063/1.3072048

View Table of Contents: http://jap.aip.org/resource/1/JAPIAU/v105/i7

Published by the American Institute of Physics.

\section{Related Articles}

Amplified spontaneous emission of Rhodamine $6 \mathrm{G}$ embedded in pure deoxyribonucleic acid Appl. Phys. Lett. 101, 171113 (2012)

Single particle demultiplexer based on domain wall conduits

Appl. Phys. Lett. 101, 142405 (2012)

Studies on CdS nanoparticles prepared in DNA and bovine serum albumin based biotemplates J. Appl. Phys. 112, 064704 (2012)

Taking whispering gallery-mode single virus detection and sizing to the limit Appl. Phys. Lett. 101, 043704 (2012)

Effect of molecule-particle binding on the reduction in the mixed-frequency alternating current magnetic susceptibility of magnetic bio-reagents

J. Appl. Phys. 112, 024704 (2012)

\section{Additional information on J. Appl. Phys.}

Journal Homepage: http://jap.aip.org/

Journal Information: http://jap.aip.org/about/about_the_journal

Top downloads: http://jap.aip.org/features/most_downloaded

Information for Authors: http://jap.aip.org/authors

\section{ADVERTISEMENT}

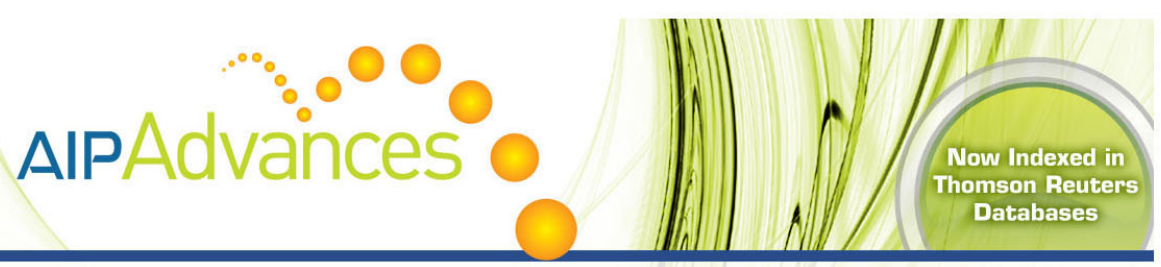

\section{Explore AIP's open access journal: - Rapid publication \\ - Article-level metrics \\ - Post-publication rating and commenting}




\title{
Synthesis of magnetic porous hollow silica nanotubes for drug delivery
}

\author{
H. Ma, ${ }^{1}$ J. Tarr, ${ }^{1}$ M. A. DeCoster ${ }^{2}$ J. McNamara, ${ }^{2}$ D. Caruntu, ${ }^{1}$ J. F. Chen, ${ }^{3}$ \\ C. J. O'Connor, ${ }^{1}$ and W. L. Zhou ${ }^{1, a)}$ \\ ${ }^{1}$ Advanced Materials Research Institute, University of New Orleans, New Orleans, Louisiana 70148, USA \\ ${ }^{2}$ Biomedical Engineering and Institute for Micromanufacturing, Louisiana Tech University, Ruston, \\ Louisiana 71270, USA \\ ${ }^{3}$ Key Laboratory for Nanomaterials, Ministry of Education, Beijing University of Chemical Technology, \\ Beijing 100029, China
}

(Presented 12 November 2008; received 22 September 2008; accepted 18 November 2008; published online 12 March 2009)

\begin{abstract}
In this paper, we report a synthesis of magnetic porous hollow silica nanotubes (MPHSNTs) using sol-gel method. The MPHSNTs were fabricated by coating $\mathrm{Fe}_{3} \mathrm{O}_{4}$ nanoparticles and silica on surfactant hexadecyltrimethylammonium bromide (CTAB) modified $\mathrm{CaCO}_{3}$ nanoneedles surface under alkaline condition. $\mathrm{CaCO}_{3}$ nanoneedles and surfactant $\mathrm{CTAB}$ are introduced as nanotemplates to form the hollow and porous structures, respectively. After removing CTAB by calcination and etching $\mathrm{CaCO}_{3}$ nanoneedles away in diluted acetic acid, magnetic porous hollow silica nanotubes with $\mathrm{Fe}_{3} \mathrm{O}_{4}$ nanoparticles embedded in the silica shell were achieved. The products were characterized by scanning electron microscopy, transmission electron microscopy, and $\mathrm{N}_{2}$ adsorption-desorption isotherms. Superconducting quantum interference device measurement shows that the nanotubes exhibit superparamagnetism property at room temperature and ferromagnetism below the blocking temperature. Toxicity test was also performed for the magnetic nanocarriers, showing good bio-compatibility. Magnetic porous hollow silica nanotubes with advantages of high surface area, good bio-compatibility, and superparamagnetism are one of the novel drug nanocarriers for nanomedicine applications. () 2009 American Institute of Physics.
\end{abstract}

[DOI: $10.1063 / 1.3072048]$

In the past few years, our group has performed a series of synthesis for magnetic hollow silica nanospheres for biomedicine applications. ${ }^{1-6}$ This kind of magnetic silica nanomaterials not only has the advantages of magnetic nanocarriers as addressed by many other literatures, ${ }^{7-10}$ but also possesses the characteristics of bio-compatibility and less toxicity. In addition, silica can be easily obtained from several precursors and remains stable in most chemical and biological environments, which is very suitable for designing multiform magnetic silica nanostructures for different applications. Many groups in different biomedical fields have also reported their interesting works on various nanostructured silica nanomaterials. ${ }^{11-13}$ Recently, our group focuses on magnetic porous hollow silica nanospheres as drug carriers, using $\mathrm{CaCO}_{3} / \mathrm{Fe}_{3} \mathrm{O}_{4}$ composite nanoparticles and cationic surfactant double sacrificial templates, ${ }^{1,2}$ in which magnetic nanoparticles were encapsulated in the hollow cores of the silica nanospheres, providing superparamagnetic characteristic at room temperature. A slow release of ibuprofen was observed due to the porous structure. ${ }^{1}$ On the other hand, silica nanotube is also another novel nanostructure that can be potentially used as carrying more drugs, compared with silica nanospheres. Different from the nanospheres exposed only outside surface, nanotubes with open ends offer both inside and outside surface to interact with drug molecules, which largely increase surface/volume ratio and improve

\footnotetext{
${ }^{a)}$ Author to whom correspondence should be addressed. Electronic mail: wzhou@uno.edu. Tel.: (504) 280-1068. FAX: (504) 280-3185.
}

drug loading capacity. In this paper, we present a synthesis of magnetic porous hollow silica nanotubes using double template method. Magnetite nanoparticles were first attached on the pure $\mathrm{CaCO}_{3}$ nanoneedle surface (first template) fabricated through rotating packed bed (RPB) method, and then followed by self-assembly of cationic surfactant hexadecyltrimethylammonium bromide (CTAB) as the second template to direct the porous formation while silica shell was being formed. After removing both the templates, porous silica nanotubes with magnetite nanoparticles embedded in the shell were achieved.

The synthesis procedure using so-gel method is similar to the one of magnetic porous silica nanospheres. ${ }^{1} \mathrm{CaCO}_{3}$ nanoneedles were first fabricated by a RPB method. ${ }^{14}$ In fact, the size of the as-prepared $\mathrm{CaCO}_{3}$ nanoneedles was inhomogeneous and hard to be directly used in the synthesis. Therefore, a size selection process was performed to achieve more homogenous nanoneedles for the later on synthesis. $20 \mathrm{~g}$ of original $\mathrm{CaCO}_{3}$ nanoneedles was ultrasonically dispersed in $200 \mathrm{ml}$ ethanol for $2 \mathrm{~h}$ then introduced to a series of centrifuging with different rates and times. Then the size of purified samples was checked with scanning electron microscope (SEM). $3 \mathrm{~g}$ size selected $\mathrm{CaCO}_{3}$ nanoneedles with the dimension of less than $1000 \mathrm{~nm}$ in length and $200 \mathrm{~nm}$ in diameter were ultrasonically dispersed in a mixture of $80 \mathrm{ml}$ ethanol (A Aper Alcohol and Chemical Co.) and $20 \mathrm{ml}$ distilled water in a three-neck flask for $25 \mathrm{~min}$. Then $0.5 \mathrm{ml}$ of a methanolic dispersion of $\mathrm{Fe}_{3} \mathrm{O}_{4}$ nanoparticles $(10.66 \mathrm{mg} /$ $\mathrm{ml}$ ) was added to the suspension above and dispersed in ul- 


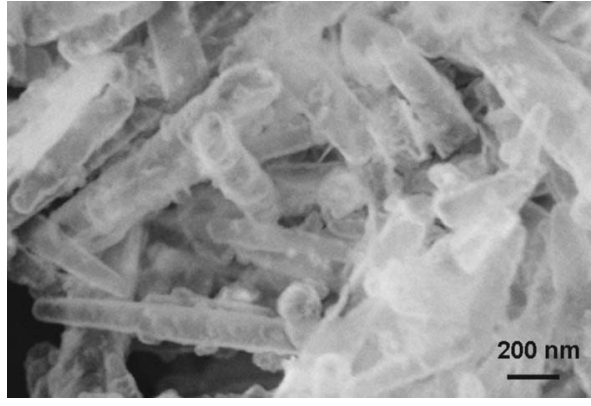

FIG. 1. FESEM micrograph of magnetic porous hollow silica nanotubes.

trasonic for another $10 \mathrm{~min}$. Superparamagnetic $\mathrm{Fe}_{3} \mathrm{O}_{4}$ nanoparticles were prepared by a method based on the hydrolysis of chelate metal alkoxide complexes at elevated temperature in solutions of diethylene glycol, which was published elsewhere. ${ }^{15}$ After that, $1 \mathrm{~g}$ of CTAB $(99+\%$; Johnson Matthew Co.) was applied to the mixture and ultrasonic dispersed for 20 min. ${ }^{16-18}$ Then the flask was settled under a mechanical stirrer and stirred at a rate of $500 \mathrm{rpm}$. Appropriate amount of ammonia (30\%; J.T. Baker) and $3.2 \mathrm{ml}$ of TEOS (99.9\%; Johnson Matthew) was added into the reaction mixture within 10 min to reach the $\mathrm{pH}$ value 11 . The system was continuously stirred at $500 \mathrm{rpm}$ for $2 \mathrm{~h}$ at room temperature, and then aged at room temperature for $4 \mathrm{~h}$. After centrifuging washing and drying, the products were introduced to calcination for first $3 \mathrm{~h}$ at $300{ }^{\circ} \mathrm{C}$, then $5 \mathrm{~h}$ at $550{ }^{\circ} \mathrm{C}$ to remove the surfactant template. After calcination, the product was immersed in diluted acetic acid (J. T. Baker) solution (HAc: $\left.\mathrm{H}_{2} \mathrm{O}=1: 15\right)$ for $4.5 \mathrm{~h}$ to remove the $\mathrm{CaCO}_{3}$ template. The product was then dried at $70{ }^{\circ} \mathrm{C}$, following two times washes with distilled water and one time with ethanol. Finally, the magnetic porous hollow silica nanotubes with magnetite nanoparticles embedded in the shell was obtained. Meanwhile, we also fabricated magnetic silica nanotubes without pores as a comparison.

A Carl Zeiss 1530 VP field emission scanning electron microscope (FESEM) and JEOL 2010 transmission electron microscope (TEM) was used to examine the morphologies of the nanotubes. EDAX (AMETEK, Inc.) energy dispersive spectroscopy (EDS) was applied to determine the composition of the products. A micromeritics ASAP 2010 analyzer was employed to measure $\mathrm{N}_{2}$ adsorption-desorption isotherms at $77 \mathrm{~K}$ to get the Barrett-Joyner-Halenda (BJH) pore size distributions. The magnetic properties were measured on a Quantum Design MPMS-5S superconducting quantum interference device (SQUID) magnetometer.

Figure 1 is a SEM image providing morphology information of the magnetic porous hollow silica nanotubes (MPHSNT). The diameter of the nanotubes is below $200 \mathrm{~nm}$ and the length is within $1000 \mathrm{~nm}$. Most of the nanotubes were broken in the middle, leaving the opened ends and exposed inner hollow space for drug loading.

Figure 2(a) is a TEM image showing the middle region of a single MPHSNT. The thickness of silica shell is about $20 \mathrm{~nm}$ and the magnetite nanoparticles with diameter about $10 \mathrm{~nm}$ appear as darker dots. It can be clearly seen that from the edge of the shells the magnetite nanoparticles (denoted

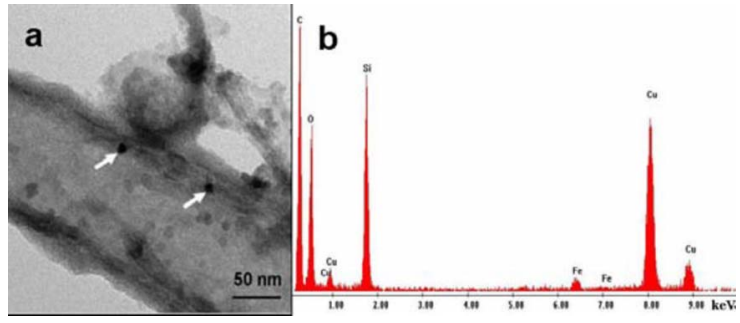

FIG. 2. (Color online) (a) TEM image of a MPHSNT showing the middle region of the nanotube. The size of the darker contrast magnetite nanoparticles is about $10 \mathrm{~nm}$. (b) The EDS spectrum of MPHSNT.

by arrows) are successfully embedded in the silica shell. Figure 2(b) is the EDS analysis showing the $\mathrm{Si}, \mathrm{Fe}$, and $\mathrm{O}$ besides the $\mathrm{C}$ and $\mathrm{Cu}$ peaks from the sample grid. Also, the absence of $\mathrm{Ca}$ peak indicates that the $\mathrm{CaCO}_{3}$ template was completely etched away by the diluted acetic acid, leaving the hollow structure.

The cationic surfactant CTAB was used as second template to direct porous structure formation in the silica shell. The pore size can be evaluated by $\mathrm{N}_{2}$ adsorption-desorption isotherms and calculated by BJH method. Compared with the samples without surfactant modification, CTAB modified nanotubes represent a quite uniform pore size distribution around $2.1 \mathrm{~nm}$. These pores behave as nanochannels run through the silica shell, providing porous structure for both inside and outside surface for drug delivery.

The magnetic properties of the MPHSNTs were measured by SQUID. Zero-field-cooled (ZFC) and field-cooled (FC) magnetization data were measured in the temperature range of 5-300 K, as shown in Fig. 3(a). In the ZFC measurement, the initial field was set to zero when cooling the sample from 300 to $5 \mathrm{~K}$. A field of 100 Oe was applied and the magnetization was measured as the sample was heated from 5 to $300 \mathrm{~K}$. In FC measurement, a field of 100 Oe was applied as the sample was cooled from 300 to $5 \mathrm{~K}$ and the magnetization was measured as the sample was heated from 5 to $300 \mathrm{~K}$ in the field of $100 \mathrm{Oe}$. The ZFC curve shows a maximum at $83.7 \mathrm{~K}$, which is the blocking temperature $\left(T_{B}\right)$ of the magnetic nanoparticles in the MPHSNTs. Such a behavior is the characteristic of superparamagnetism and is due to the progressive blocking of the magnetic moment of the nanoparticles when decreasing the temperature. The MPHSNTs exhibit superparamagnetism and ferromagnetism above and below the blocking temperature, respectively. To ensure these features, the field-dependent hysteresis loops of the MPHSNTs were measured at temperatures both above and below the blocking temperature as shown in Fig. 3(b). The hysteresis loop at $5 \mathrm{~K}$ shows a saturation magnetization of $1.35 \mathrm{emu} / \mathrm{g}$ (at the field of $10000 \mathrm{Oe}$ ) and a coercivity of 152 Oe, which confirms that the MPHSNTs are ferromagnetic below the blocking temperature. The absence of coercivity in the hysteresis loop at $300 \mathrm{~K}$ indicates a superparamagnetic behavior. The MPHSNTs have superparamagnetic properties, which means they can be attracted by a magnetic field but retain no residual magnetism when the magnetic field is removed at room temperature.

The drug loading and releasing study for MPHSNTs is still under processing. However, according to our previously 
a

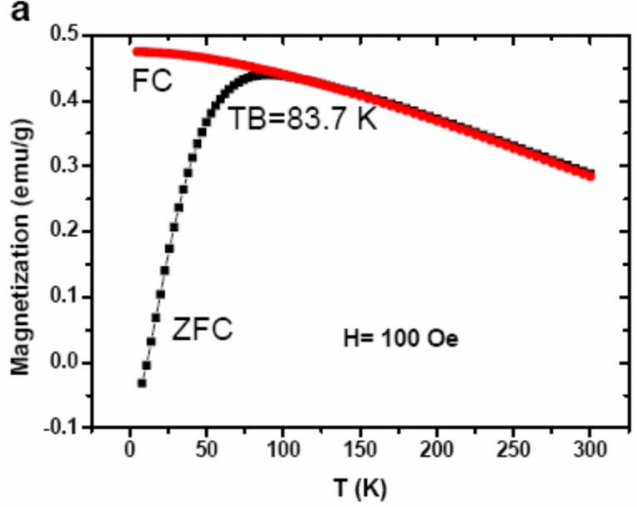

b

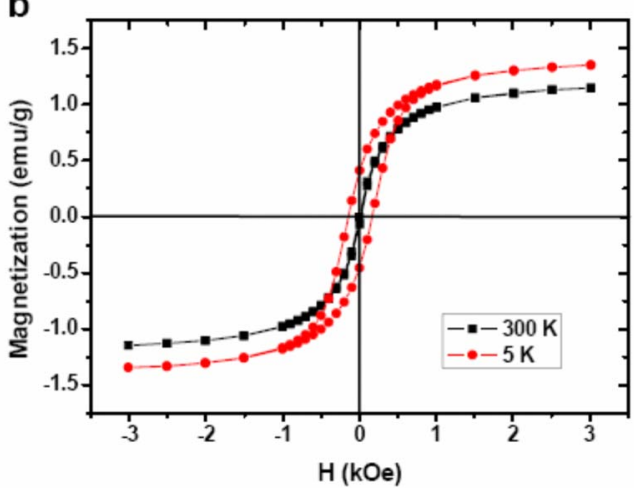

FIG. 3. (Color online) Magnetic properties of the MPHSNTs. (a) Temperature dependence of magnetization at ZFC and FC conditions and (b) hysteresis loops of the MPHSNTs at 5 and $300 \mathrm{~K}$, respectively.

published result, the drug-loading efficiency for $75 \mathrm{mg}$ magnetic porous hollow silica nanospheres synthesized using the similar method with porous nanotubes was $14.21 \%$ from 1.8 $\mathrm{mg} / \mathrm{ml}$ ibuprofen/hexane solution. ${ }^{1}$ Since nanotubes exposed both the inside and outside surface which results in an increased surface/volume ratio, comparing with nanospheres, we have reason to estimate that the drug loading efficiency for MPHSNTs will be the same as, or even better, than the one of nanospheres.

Toxicity test was also performed to assess the biocompatibility of MPHSNT. Rat brain cells were exposed to MPHSNT and copper nanoparticles in a concentration of $50 \mu \mathrm{g} / \mathrm{ml}$, respectively. The cells were incubated with the nanosamples for $4.5 \mathrm{~h}$ under normal growth conditions in a $5 \% \mathrm{CO}_{2}$ incubator, and then differently stained to show both the dead and live cells under microscope. Compared with blank control group which was incubated without any nanosamples, the cells treated with copper nanoparticles are injured and died; but cells exposed to MPHSNT appear similar to control cells, in both amount and morphology aspects.
This means the MPHSNT has quite low toxicity effect to the brain cell showing bio-compatibility.

In summary, the magnetic porous hollow silica nanotubes were fabricated using double-template method. The nanotubes with diameter less than $200 \mathrm{~nm}$ and pore size about $2.1 \mathrm{~nm}$ were formed after the calcination and weak acid etching. The magnetite nanoparticles were embedded in the silica shell and provide superparamagnetism for the MPHSNTs at room temperature. The pores as nanochannels connect inside and outside shell surface together for drug carrying and delivering. Also, toxicity test demonstrates that the MPHSNTs are biocompatible and potentially useful for targeted delivery and controlled release.

We gratefully acknowledge the support of this work by the DARPA Grant No. HR0011-07-1-0032 and a research grant from Louisiana Board of Regents Contract No. LEQSF(2007-12)-ENH-PKSFI-PRS-04. W.L.Z. acknowledges the partial support from the Research Fund of Key Laboratory for Nanomaterials, Ministry of Education (Grant No. 2007-1).

${ }^{1}$ J. Zhou, W. Wu, D. Caruntu, M. H. Yu, A. Martin, J. F. Chen, C. J. O'Connor, and W. L. Zhou, J. Phys. Chem. C 111, 17473 (2007).

${ }^{2}$ H. Ma, J. Zhou, D. Caruntu, M. H. Yu, J. F. Chen, C. J. O'Connor, and W. L. Zhou, J. Appl. Phys. 103, 07A320 (2008).

${ }^{3}$ L. Shao, D. Caruntu, J. F. Chen, C. J. O'Connor, and W. L. Zhou, J. Appl. Phys. 97, 10Q908 (2005).

${ }^{4}$ W. Wu, M. A. DeCoster, B. M. Daniel, J. F. Chen, M. H. Yu, D. Cruntu, C. J. O'Connor, and W. L. Zhou, J. Appl. Phys. 99, 08H104 (2006).

${ }^{5}$ W. Zhou, P. Gao, L. Shao, D. Caruntu, M. Yu, J. Chen, and C. J. O'Connor, Nanomedicine 1, 233 (2005)

${ }^{6}$ W. Wu, D. Caruntu, A. Martin, M. H. Yu, C. J. O'Connor, W. L. Zhou, and J.-F. Chen, J. Magn. Magn. Mater. 311, 578 (2007).

${ }^{7}$ H. H. Yang, S. Q. Zhang, X. L. Chen, Z. X. Zhuang, J. G. Xu, and X. R. Wang, Anal. Chem. 76, 1316 (2004).

${ }^{8}$ B. I. Haukanes and C. Kvam, Nat. Biotechnol. 11, 60 (1993).

${ }^{9}$ T. Tanaka and T. Matsunaga, Anal. Chem. 72, 3518 (2000).

${ }^{10}$ L. Levy, Y. Sahoo, K. S. Kim, E. J. Bergey, and P. N. Prasad, Chem. Mater. 14, 3715 (2002).

${ }^{11}$ F. Caruso, R. Caruso, and H. Mohwald, Science 282, 1111 (1998).

${ }^{12}$ K. M. K. Yu, D. Thompsett, and S. C. Tsang, Chem. Commun. 13, 1522 (2003).

${ }^{13}$ J. F. Chen, H. M. Ding, J. X. Wang, and L. Shao, Biomaterials 25, 723 (2004).

${ }^{14}$ J. Chen, Y. Wang, F. Guo, X. Wang, and C. Zheng, Ind. Eng. Chem. Res. 39, 948 (2000).

${ }^{15}$ D. Caruntu, G. Caruntu, Y. C. Chen, C.-J. O'Connor, G. Goloverda, and V.-L. Kolesnichenko, Chem. Mater. 16, 5527 (2004).

${ }^{16}$ Y. Lu, Y. Yang, A. Sellinger, M. Lu, J. Huang, H. Fan, R. Haddad, G. Lopez, A. R. Burns, D. Y. Sasaki, J. Shelnutt, and C. J. Brinker, Nature (London) 410, 913 (2001).

${ }^{17}$ D. Wang, W. L. Zhou, B. F. McCaughy, J. E. Hampsey, X. Ji, Y. B. Jiang, H. Xu, J. Tang, R. H. Schmehl, C. J. O'Connor, C. J. Brinker, and Y. Lu, Adv. Mater. (Weinheim, Ger.) 15, 130 (2003).

${ }^{18}$ Y. Lu, Angew. Chem. Int. Ed. 45, 7664 (2006). 